\title{
Francisella tularensis/Rickettsia spp. co-infections in patients with skin changes and lymphadenopathy
}

\author{
Tomasz Chmielewski, Beata Fiecek, Grażyna Lewandowska, Waldemar Rastawicki, \\ Stanisława Tylewska-Wierzbanowska
}

National Institute of Public Health - National Institute of Hygiene, Warsaw, Poland

Submitted: 19 June 2015

Accepted: 12 September 2015

Arch Med Sci 2018; 14, 2: 357-360

DOI: 10.5114 /aoms.2016.60505

Copyright (c) 2016 Termedia \& Banach

\section{Abstract}

Introduction: Tularemia and spotted fever group rickettsioses (SFG) can be transmitted by ticks and have a number of common clinical symptoms. Most characteristic are a maculopapular or vesicular rash or an eschar at the site of the tick or insect bite accompanied by painful lymph nodes. The aim of this study was to determine whether Rickettsia spp./Francisella tularensis mixed infections occurred in patients with similar symptoms who were diagnosed with either Rickettsia spp. or F. tularensis infection.

Material and methods: Thirty-six cases from 2011-2014, including 15 individuals with clinically and serologically recognized SFG and 21 with tularemia, were analyzed retrospectively using immunofluorescence for detection of Rickettsia spp. or ELISA for detection of $F$. tularensis.

Results: Of the 36 cases examined, specific high titers of antibodies to Rickettsia spp. were found in 1 (4.4\%) patient with tularemia and specific high titers of antibodies to F. tularensis were detected in 1 (6.7\%) patient with SFG. Conclusions: The results of our study show that in infections with fever, enlarged lymph nodes and skin lesions after tick and insect bites, laboratory testing of both diseases - SFG rickettsiosis and tularemia - should be implemented. Identification of $F$. tularensis and Rickettsia spp. mixed infections is crucial in order to administer appropriate antibiotics and to avoid treatment failure and relapse.

Key words: rickettsiosis, tularemia, co-infection.

\author{
Corresponding author: \\ Assoc. Prof. Tomasz \\ Chmielewski MD, PhD \\ National Institute \\ of Public Health \\ National Institute of Hygiene \\ 24 Chocimska St \\ 00-791 Warsaw, Poland \\ Phone: +48 607624400 \\ E-mail: tchmielewski@pzh. \\ gov.pl
}

\section{Introduction}

Tularemia and spotted fever group rickettsioses (SFG) can be transmitted by ticks and have a number of common clinical symptoms. In Poland, both diseases are not often recognized.

Tularemia is caused by Francisella tularensis - a Gram-negative bacterium, pathogenic for many wild animals and humans. They are able to survive in a humid environment for a long time. The infection is transmitted by insect bites of various species of horseflies and mosquitoes. The other possibilities are contacts between hunters, foresters and farmers and the infected animals, inhalation of infected aerosols or dust or by consumption of contaminated water [1, 2]. Spotted fever group rickettsioses (SFG) are caused by Rickettsia spp. [3, 4]. In Poland three species are considered to be the etiological agent of the infections: $R$. slovaca, $R$. raoultii and $R$. helvetica. They are transmitted by Ixodes and Dermacentor ticks [5]. 
Both infections usually affect individuals with a history of being in a wooded area.

The incubation time of tularemia from infection to onset of symptoms ranges from 3 to 5 days. A painless ulcer appears at the site of the bite and evolves to a scar. Local lymph nodes are enlarged and they are usually painful. In about one third of the cases lymph nodes suppurate. Ulceroglandular and glandular forms are the most common for this infection. Systemic symptoms include fever, chills, malaise, fatigue and sleepiness. Patients may also complain of a headache and a sore throat [2].

The incubation time of SFG rickettsioses is usually 1 week (1-15 days). The characteristic symptoms are a maculopapular or vesicular rash or an eschar at the site of the tick bite accompanied by painful lymph nodes. General symptoms associated with acute rickettsial infections are nonspecific and include fever, headache, malaise, and sometimes nausea and vomiting [4].

Due to the similar clinical picture of both diseases, the aim of our study was to determine whether Rickettsia spp./Francisella tularensis mixed infections occurred in patients who were diagnosed with either Rickettsia spp. or F. tularensis infection.

\section{Material and methods}

Thirty-six cases from the years 2011-2014, including 15 individuals with clinically and serologically recognized SFG and 21 with tularemia, were analyzed retrospectively. The mean age of the patients was 36 years; 28 (78\%) of the patients were male and 8 (22\%) female. Detailed anamnesis was obtained from 23 patients. All of them presented with skin changes and lymphadenopathy.
For detection of IgM and IgG Rickettsia spp. antibodies, microimmunofluorescence (MIF) was used as the reference method for serodiagnosis of rickettsioses, with inactivated $R$. typhi and $R$. rickettsii antigens (Rickettsia IFA IgM, Rickettsia IFA IgG, Focus diagnostic, USA).

Specific IgM and IgG antibodies to F. tularensis were tested with Serion ELISA classic Francisella tularensis IgG/IgM (Institut Virion/Serion GmbH, Wurzburg, Germany).

\section{Results}

We tested the serum from 36 patients who had a confirmed diagnosis of either SFG or tularemia infection. Of these 36, 15 individuals had a confirmed SFG infection and 21 had a confirmed tularemia infection.

Of the 21 patients with a confirmed tularemia infection, we detected antibodies against Rickettsia spp. in 10 (47.6\%) patients. Of these, 6 (28.6\%) patients had non-significant, low-level antibodies (titer of $1: 32$ ) and $3(14.3 \%)$ patients had low-level antibodies (titer of 1 : 64) against Rickettsia spp. (data not shown). A single patient (4.4\%) had a specific high titer of $1: 128$ to Rickettsia spp. (Table I).

Of the 15 patients with confirmed SFG infection, 3 (20\%) had antibodies to F. tularensis. Of these patients, 1 had a specific high titer to $F$. tularensis (Table I).

Co-infections of $F$. tularensis and Rickettsia spp. were recognized on the basis of a high level of antibodies in the $2(5.5 \%)$ patients described above. The first patient had been recognized as a tularemia case in June 2013 (case 1) and SFG had been recognized in the second patient in August of the same year (case 2).

Table I. Clinical symptoms and results of diagnostic tests in patients with mixed infection

\begin{tabular}{|c|c|c|c|c|c|c|c|}
\hline \multirow[t]{2}{*}{ Case } & \multirow{2}{*}{$\begin{array}{c}\text { Clinical diagnosis } \\
\text { (symptoms of disease) }\end{array}$} & \multirow{2}{*}{$\begin{array}{c}\text { Day of } \\
\text { symptoms }\end{array}$} & \multicolumn{2}{|c|}{ F. tularensis ELISA ${ }^{2}$} & \multicolumn{2}{|c|}{ R. rickettsii IFA ${ }^{3}$} & \multirow[t]{2}{*}{ Treatment } \\
\hline & & & IgM & IgG & $\lg M$ & IgG & \\
\hline \multirow[t]{2}{*}{1} & $\begin{array}{l}\text { Fever up to } 39^{\circ} \mathrm{C} \text {, ulcer } \\
\text { in the left popliteal } \\
\text { fossa with regional } \\
\text { lymphadenopathy, } \\
\text { tachycardia, chills, } \\
\text { significant weakness } \\
\text { and malaise, fatigue }\end{array}$ & 35 & 165 & 100 & Negative & $1: 128$ & $\begin{array}{l}\text { Ceftazidime ( } 2.0 \mathrm{~g} / \text { day }) \\
\text { and clarithromycin } \\
(500 \mathrm{mg} / \text { day }) \\
\text { Meropenem ( } 1.5 \mathrm{~g} / \text { day }) \\
\text { with vancomycin } \\
(1.5 \mathrm{~g} / \text { day }) \\
\text { Doxycycline } \\
\text { (200 mg/day) }\end{array}$ \\
\hline & $\begin{array}{l}\text { Asymptomatic - } \\
\text { treatment control }\end{array}$ & 105 & 36 & 130 & Negative & $1: 64$ & \\
\hline 2 & $\begin{array}{l}\text { Fever up to } 39^{\circ} \mathrm{C} \text {, } \\
\text { suppurating eschar } \\
\text { on the right lower } \\
\text { leg, regional } \\
\text { lymphadenopathy }\end{array}$ & 14 & 104 & 100 & Negative & $1: 512$ & $\begin{array}{l}\text { Doxycycline } \\
\text { (200 mg/day) }\end{array}$ \\
\hline
\end{tabular}

${ }^{1}$ Patients were tested on various days of disease symptoms. ${ }^{2}$ Level of specific antibodies to $F$. tularensis according to ELISA test: IgM antibodies positive $>25, \mathrm{lgG}$ antibodies positive $>12 .{ }^{3} \mathrm{lgG}$ serum antibodies endpoint titers of R. rickettsii according to IFA test: $1: 256$ and greater are considered presumptive evidence of recent or current infection, $<1: 256$ and $\geq 1: 64$ past or early infection, < $1: 64$ no antibody detected. 
Case 1: A 39-year-old man was admitted to the hospital in June of 2013 for fever up to $39^{\circ} \mathrm{C}$ with chills, significant weakness and malaise and fatigue for 2 weeks. A few days before the appearance of symptoms the patient has been bitten by an insect in the left popliteal fossa with subsequent swelling and inflammatory infiltration. Physical examination on admission revealed tachycardia to 120 beats/min, ulcer in the left popliteal fossa and packages of enlarged (up to several $\mathrm{cm}$ ) lymph nodes in the left groin. In laboratory blood tests, moderate leukocytosis (13 000 cells/ $\mu \mathrm{l})$ and elevated C-reactive protein (CRP) $(40 \mathrm{mg} / \mathrm{l})$ were noted. The patient was treated intravenously with ceftazidime ( $2.0 \mathrm{~g} /$ day) and clarithromycin (500 mg/day). The results of Lyme disease serological tests were negative. The treatment was modified using meropenem ( $1.5 \mathrm{~g} /$ day) with vancomycin ( $1.5 \mathrm{~g} /$ day) after 3 days due to the lack of improvement. Fever and chills subsided and an ulcer in the popliteal fossa healed up, but tachycardia, perspiration occurring 3-5 times a day and swollen lymph nodes in the left groin persisted. After a few days, despite antibiotic treatment, one of the enlarged lymph nodes suppurated, and was surgically removed. During 3 weeks of hospitalization the intensity of all symptoms decreased. Prior to discharge, blood tests for tularemia and SFG rickettsiosis were performed. Both diseases were confirmed with serology. Treatment with doxycycline (200 mg/day) was ordered. Over the next week the symptoms resolved completely.

Case 2: A 51-year-old man was admitted to the hospital in August of 2013 for fever up to $39^{\circ} \mathrm{C}$ with a suppurating eschar on the right lower leg. In the right inguinal area multiple enlarged lymph nodes were found. He reported that he had been bitten by an insect a few days earlier. SFG rickettsiosis or tularemia was suspected. The immunofluorescence test with $R$. rickettsii antigen showed a high titer of IgG class of antibodies. Specific IgG and IgA antibodies to $F$. tularensis were detected as well. Doxycycline (200 mg/day) was used in treatment.

\section{Discussion}

The results of our serological testing indicate that Rickettsia spp./F. tularensis co-infections may occur in humans in Poland. Infections caused by both pathogens separately have been described as the SENLAT syndrome - scalp eschar and neck lymphadenopathy after tick bite [6-9].

In nature, Rickettsia spp. and F. tularensis have been found in host-feeding and questing ticks in Germany [10], Austria [11], and Czechoslovakia [12]. Both pathogens have been found in ticks of the genera Dermacentor and Ixodes - the most prevalent arthropod vectors capable of infection dissemination in Poland as well as in Europe [5]. The occurrence of Rickettsia spp. in ticks depends on the species and geographical location in the country. They were detected in up to $26 \%$ of $I$. ricinus and $57 \%$ of $D$. reticulatus ticks $[5,10,13,14]$.

Co-infections with $F$. tularensis and other tickborne pathogens have been described so far in ticks and reservoir animals. However, it depends on bacterial species and strains as well as the ability to survive and to transmit the disease agent to a susceptible host $[15,16]$. The most potent in circulation in ticks seem to be Borrelia burgdorferi sensu lato, Anaplasma spp., and F. tularensis. Species specificity of small mammals as the reservoir for various tick-borne pathogens determines the possibility of co-infections. It has been found that Rattus rattus could be a host for both B. burgdorferi and F. tularensis, whereas in Apodemus agrarius and Mus musculus these three pathogens can occur separately only. Rickettsia spp./F. tularensis co-infection in animals thus far was detected in Clethrionomys glareolus and Microtus arvalis, but there are no data on such cases in humans $[17,18]$.

The outcome of the distribution of these microorganisms in ticks is human infections, particularly in professional groups with high risk of acquiring tick-borne disease. The presence of antibodies to SFG rickettsiae has been detected in $14.7 \%$ to $36.0 \%$ of forest workers in Poland [19]. The prevalence of antibodies to $F$. tularensis among forest workers is $2.1 \%$ to $3.2 \%$ of tested individuals in Poland [20-22]. Seroprevalence data on risk groups indicate that neither SFG rickettsioses nor tularemia is a rare disease, as has been reported in many countries of Europe $[1,2,23,24]$, and mixed infection may occur not only in Poland but in also other geographical areas outside of Europe.

Performing serological tests, cross-reactions should be taken into consideration. It has been found that in some patients examined for tularemia, false positive results were obtained due to the presence of cross reacting antibodies to Yersinia, Brucella, Salmonella and Legionella [25]. Until now, cross reactions in rickettsial infections have been detected among antigens of bacteria within the genus Rickettsia only [3].

Recognition of rickettsiosis/tularemia co-infections in humans is of great importance for correct antibiotic treatment. Doxycycline (200 mg/day) remains the treatment of choice for tick-transmitted rickettsioses. In patients with severe hypersensitivity to tetracyclines, chloramphenicol can be considered as an alternate therapy, but its use is limited by side effects. Other broad-spectrum antibiotics, including penicillins, cephalosporins, and aminoglycosides, are ineffective for rickettsial diseases [7]. 
The drugs of choice for tularemia in humans are aminoglycosides. Due to their ototoxicity and nephrotoxicity they are now rarely used (in the most serious cases only). Chloramphenicol is also effective but seldom used due to its possible side effects on hematopoiesis. Fluoroquinolones, such as ciprofloxacin, have been shown to be highly efficacious drugs in the treatment of uncomplicated tularemia, especially in infected children and pregnant women. Tetracyclines including doxycycline are effective, but are associated with treatment failures [26].

Treatment with doxycycline of both patients resulted in rapid improvement of the health status. This indicates the effectiveness of this antibiotic in confirmed mixed infections of F. tularensis/ Rickettsia spp., although this thesis requires wider studies and a larger group of patients.

In conclusions, the results of our study show that in infections with fever, enlarged lymph nodes and skin lesions after tick and insect bites, laboratory testing of both diseases - SFG rickettsiosis and tularemia - should be implemented. Fast, accurate identification of $F$. tularensis and Rickettsia spp. mixed infections is crucial in order to administer appropriate antibiotics and to avoid treatment failure and relapse.

\section{Acknowledgments}

Financial support: grant NCN 2011/03/B/ NZ7/03788, NIPH-NIH funds (18/EM/2015).

\section{Conflict of interest}

The authors declare no conflict of interest.

\section{References}

1. Ellis J, Oyston PC, Green M, Titball RW. Tularemia. Clin Microbiol Rev 2002; 15: 631-46.

2. Petersen JM, Mead PS, Schriefer ME. Francisella tularensis: an arthropod-borne pathogen. Vet Res 2009; 40: 7-10.

3. Brouqui P, Parola P, Fournier PE, Raoult D. Spotted fever rickettsioses in southern and eastern Europe. FEMS Immunol Med Microbiol 2007; 49: 2-12.

4. Parola P, Rovery C, Rolain JM, Brouqui P, Davoust B, Raoult D. Rickettsia slovaca and R. raoultii in Tick-borne Rickettsioses. Emerg Infect Dis 2009; 15: 1105-8.

5. Chmielewski T, Podsiadly E, Karbowiak G, TylewskaWierzbanowska S. Rickettsiae spp. in ticks, Poland. Emerg Inf Dis 2009; 15: 486-8.

6. Angelakis E, Pulcini C, Waton J, et al. Scalp eschar and neck lymphadenopathy caused by Bartonella henselae after Tick Bite. Clin Infect Dis 2010; 50: 549-51.

7. Parola P, Paddock CD, Raoult D. Tick-borne rickettsioses around the world: emerging diseases challenging old concepts. Clin Microbiol Rev 2005; 18: 719-56.

8. Moniuszko A, Pancewicz SA, Czupryna P, et al. Glandular form of tularemia after arthropod bite: cases report. Przegl Epidemiol 2010; 64: 73-5.
9. Świtaj K, Chmielewski T, Borkowski P, Tylewska-Wierzbanowska S, Olszyńska-Krowicka M. Spotted fever rickettsiosis caused by Rickettsia raoulti - case report. Przegl Epidemiol 2012; 66: 347-50.

10. Maurin M, Pelloux I, Brion JP, Del Banõ JN, Picard A. Human tularemia in France, 2006-2010. Clin Infect Dis 2011; 53: 133-41.

11. Gurycová D, Tináková K, Výrosteková V, Gacíková E. The incidence of tularemia in Slovakia in 1997-2008. Epidemiol Mikrobiol Imunol 2010; 59: 39-44.

12. Franke J, Fritzsch J, Tomaso H, Straube E, Dorn W, Hildebrandt $A$. Coexistence of pathogens in host-seeking and feeding ticks within a single natural habitat in Central Germany. Appl Environ Microbiol 2010; 76: 6829-36.

13. Stanek G. Pandora's box: pathogens in Ixodes ricinus ticks in Central Europe. Wien Klin Wochenschr 2009; 121: 673-83.

14. Hubalek Z, Halouzka J. Mosquitoes (Diptera: Culicidae), in contrast to ticks (Acari: Ixodidae), do not carry Francisella tularensis in a natural focus of tularemia in the Czech Republic. J Med Entomol 1997; 34: 660-3.

15. Wójcik-Fatla A, Zając V, Sawczyn A, Cisak E, Sroka J, Dutkiewicz J. Occurrence of Francisella spp. in Dermacentor reticulatus and Ixodes ricinus ticks collected in eastern Poland. Ticks Tick Borne Dis 2015; 6: 253-7.

16. Reis C, Cote M, Paul RE, Bonnet S. Questing ticks in suburban forest are infected by at least six tick-borne pathogens. Vector Borne Zoonotic Dis 2010; 11: 907-16.

17. Podsiadły E, Chmielewski T, Karbowiak G, Kędra E, Tylewska-Wierzbanowska S. The occurrence of spotted fever rickettsioses and other tick-borne infections in forest workers in Poland. Vector-borne and Zoonotic Diseases 2010; 11: 985-9.

18. Rastawicki W, Kurowska J, Hermanowska-Szpakowicz T, Pancewicz SA, Kondrusik M, Jagielski M. Prevalence of antibodies to Francisella tularensis in forest workers from different regions of Poland. Med Dosw Mikrobiol 2006; 58: 207-15.

19. Żukiewicz-Sobczak W, Zwoliński J, Chmielewska-Badora J, et al. Prevalence of antibodies against selected zoonotic agents in forestry workers from eastern and southern Poland. Ann Agric Environ Med 2014; 21: 767-70.

20. Zając V, Wójcik-Fatla A, Cisak E, Sroka J, Sawczyn A, Dutkiewicz J. Study on tick-borne rickettsiae in eastern Poland. II. Serological response of the occupationally exposed populations. Ann Agric Environ Med 2013; 20: 280-2.

21. Foley JE, Nieto NC. Tularemia. Vet Microbiol 2010; 140: 332-8.

22. Reese SM, Dietrich G, Dolan MC, et al. Transmission dynamics of Francisella tularensis subspecies and clades by nymphal Dermacentor variabilis (Acari: Ixodidae). Am J Trop Med Hyg 2010; 83: 645-52.

23. Reese SM, Petersen JM, Sheldon SW, et al. Transmission efficiency of Francisella tularensis by adult American dog ticks (Acari: Ixodidae). J Med Entomol 2011; 48: 884-90.

24. Christova I, Gladnishka T. Prevalence of infection with Francisella tularensis, Borrelia burgdorferi sensu lato and Anaplasma phagocytophilum in rodents from an endemic focus of tularemia in Bulgaria. Ann Agric Environ Med 2005; 12: 149-52.

25. Výrosteková V, Khanakah G, Kocianová E, Gurycová D, Stanek G. Prevalence of coinfection with Francisella tularensis in reservoir animals of Borrelia burgdorferi sensu lato. Wien Klin Wochenschr 2002; 114: 482-8.

26. Carvalho CL, Lopes de Carvalho I, Zé-Zé L, Núncio MS, Duarte EL. Tularaemia: a challenging zoonosis. Comp Immunol Microbiol Infect Dis 2014; 37: 85-96. 